\title{
Lipoprotein(a) and Cardiovascular Disease in Ethnic Chinese: The Chin-Shan Community Cardiovascular Cohort Study
}

\author{
Kuo-Liong Chien, ${ }^{1,2 *}$ Hsiu-Ching Hsu, ${ }^{2}$ Ta-Chen Su, ${ }^{2}$ Fung-Chang Sung, ${ }^{3}$ Ming-Fong Chen, ${ }^{2}$ \\ and Yuan-Teh Lee Le** $^{*}$
}

BACKGROUND: Little is known about lipoprotein(a) $[\operatorname{Lp}(\mathrm{a})]$ as a predictor of vascular events among ethnic Chinese. We prospectively investigated the association of $\mathrm{Lp}(\mathrm{a})$ with cardiovascular disease and all-cause death in a community-based cohort.

METHODS: We conducted a community-based prospective cohort study of 3484 participants (53\% women; age range, 35-97 years) who had complete lipid measurements and were free of a cardiovascular disease history at the time of recruitment. Over a median follow-up of 13.8-years, we documented 210 cases of stroke, 122 cases of coronary heart disease (CHD), and 781 deaths.

RESULTS: The incidences for each event increased appreciably with $\mathrm{Lp}(\mathrm{a})$ quartile for stroke and all-cause death, but not for CHD. Baseline $\mathrm{Lp}$ (a) concentration by quartile was not significantly associated with stroke, all-cause death, and CHD in multivariate analyses. The multivariate relative risk was significant for stroke at the 90th and 95th percentiles and for total death at the 95th and 99th percentiles.

CONCLUSIONS: Our findings suggest a threshold relationship with little gradient of risk across lower Lp(a) values for stroke and all-cause death in Chinese adults. (C) 2007 American Association for Clinical Chemistry

Lipoprotein(a) $[\operatorname{Lp}(a)]^{5}$ is a low-density lipoprotein particle in which apolipoprotein B-100 is linked by a single disulfide bridge to apolipoprotein(a), which is structurally similar to plasminogen $(1,2)$. The dual effects of atherogenicity and thrombogenesis from $\mathrm{Lp}(\mathrm{a})$ particles make it plausible to investigate the role of
$\mathrm{Lp}(\mathrm{a})$ in atherosclerosis in a population; however, although many cross-sectional studies of hospital-based populations have consistently shown that $\mathrm{Lp}(\mathrm{a})$ is related to various vascular diseases (3-6), the evidence provided by many prospective cohort studies has been equivocal. In addition, previous large-scale prospective cohorts were restricted to women (7), to men $(8)$, or to an older population $(9,10)$. Moreover, most studies have specified only one vascular outcome, either coronary heart disease (CHD) or stroke, whereas some studies have combined both outcomes into just one endpoint (9). Furthermore, the risk of $\operatorname{Lp}(\mathrm{a})$ with respect to cardiovascular events has varied according to ethnicity (11). Few prospective studies have investigated the role of $\operatorname{Lp}(\mathrm{a})$ among ethnic Chinese, who have cardiovascular disease patterns distinct from those of Caucasians and African Americans. Therefore, we prospectively investigated the association of plasma $\mathrm{Lp}(\mathrm{a})$ concentration with cardiovascular disease and all-cause death among ethnic Chinese in Taiwan.

\section{Materials and Methods}

STUDY DESIGN AND STUDY PARTICIPANTS

The participants were enrolled in the Chin-Shan Community Cardiovascular Study, a prospective community-based study of risk factors and cardiovascular consequences in men and women 35 years of age or older sponsored by the National Science Council, Taiwan. The study was started in 1990 with an initial cohort of 3602 participants, who were recruited on the basis of official registrations. The institutional review boards of the National Taiwan University approved the study. These participants were noninstitutionalized persons who gave oral informed consent to enter and

\footnotetext{
${ }^{1}$ Institute of Preventive Medicine, College of Public Health, National Taiwan University, Taipei, Taiwan; ${ }^{2}$ Department of Internal Medicine, National Taiwan University Hospital, Taipei, Taiwan; ${ }^{3}$ Institute of Environmental Health, College of Public Health, China Medical University, Taichung, Taiwan; ${ }^{4}$ Ming-Sheng Healthcare, Taoyuang, Taiwan.

* Address correspondence to these authors at: Department of Internal Medicine, National Taiwan University Hospital, Taipei, Taiwan, 100. e-mail ytlee@ ha.mc.ntu.edu.tw.
}

Received April 27, 2007; accepted November 15, 2007.

Previously published online at DOI: 10.1373/clinchem.2007.090969

${ }^{5}$ Nonstandard abbreviations: Lp(a), lipoprotein(a); CHD, coronary heart disease; HDL-C, HDL cholesterol; LDL-C, LDL cholesterol; RR, relative risk; Cl, confidence interval. 
to remain in the study. Participants were eligible for enrollment regardless of whether they had a history of cardiovascular disease. The full details of the recruitment process have been published elsewhere $(12,13)$. In brief, the study collected information regarding medical history, the results of a physical examination and laboratory tests, and an assessment of health status that included any evidence of cardiovascular disease in 1990 and 1991 and the follow-up periods (14-16). We also collected detailed information about lifestyle factors, including alcohol intake, smoking, and regular exercise, as well as data regarding socioeconomic status, including marital status, educational level, and family history of CHD. We defined the cardiovascular disease at baseline according to the responses in the questionnaire about the history of stroke and CHD events. With regard to the follow-up schedule, we gathered information about cardiovascular events and deaths through monthly collections of official death certificate documents, by annual questionnaires, and by house-to-house visits.

\section{ASCERTAINMENT OF EVENTS}

The study outcomes were stroke, CHD, and all-cause death. Stroke was defined as a sudden neurologic deficit of vascular origin that lasted longer than $24 \mathrm{~h}$ that was supported by evidence from an imaging study. Transient ischemic attacks were not included in this definition. Incident CHD cases were defined as nonfatal myocardial infarction, fatal CHD, and hospitalization for percutaneous coronary intervention and coronary artery bypass surgery. Fatal CHD was considered to have occurred if fatal myocardial infarction was confirmed by hospital records, if CHD was listed as the cause of death on the death certificate or was the underlying and most plausible cause of death, or if evidence of previous CHD was available. Deaths from any cause were identified from official certificate documents and further verified by house-to-house visits.

\section{MEASUREMENTS OF BIOCHEMICAL VARIABLES}

The procedures of blood sampling have been reported elsewhere $(15,17)$. In brief, all venous blood samples drawn after a 12 -h overnight fast were immediately refrigerated and transported within $6 \mathrm{~h}$ to the $\mathrm{Na}-$ tional Taiwan University Hospital. Serum samples were then stored at $-70{ }^{\circ} \mathrm{C}$ before batch assay of total cholesterol, triglycerides, and HDL cholesterol (HDLC). Standard enzymatic tests for serum cholesterol and triglycerides were used (Merck 14354 and 14366, respectively). HDL-C concentrations were measured in supernatants after precipitation with magnesium chloride/phosphotungstate reagents (Merck 14993). The LDL cholesterol (LDL-C) concentration was calculated as the total cholesterol concentration minus the concentration of cholesterol in the supernatant obtained with the precipitation method (Merck 14992) (18). The concentrations of apolipoproteins A-I and B were measured by turbidimetric immunoassay (19) with commercially available kits (Sigma-Aldrich). The concentration of non-HDL cholesterol was calculated by subtracting the HDL-C concentration from the concentration of total cholesterol. $\mathrm{Lp}(\mathrm{a})$ was measured by isoform-independent ELISA (Organon). The CV for $\mathrm{Lp}(\mathrm{a})$ measurements was $5 \%$. In this study, we included 3484 participants who had complete $\mathrm{Lp}(\mathrm{a})$ measurements and were free from cardiovascular disease at baseline.

\section{STATISTICAL ANALYSIS}

Participants were classified by quartile of $\operatorname{Lp}(\mathrm{a})$ concentration, and continuous variables were presented as the mean $(\mathrm{SD})$ or the median; categorical data were presented in contingency tables. ANOVA and the $\chi^{2}$ test were used to test differences between quartiles. Relationships between baseline $\mathrm{Lp}$ (a) concentrations and other obesity and lipid markers were evaluated with age- and sex-adjusted Spearman partial correlation coefficients.

Incidence rates for stroke, $\mathrm{CHD}$, and all-cause death were calculated for each $\mathrm{Lp}(\mathrm{a})$ quartile by dividing the number of cases by the number of person-years of follow-up. The relative risk (RR) of an event was calculated by dividing the incidence rate for each quartile by the rate in the first quartile. We used Cox proportional hazards models to adjust for potential confounding variables. We specified 5 models for estimating the RRs of events in higher $\operatorname{Lp}(\mathrm{a})$ quartiles relative to the lowest quartile. In model 1 , we estimated the univariate $R R$ of $L p(a)$ concentration with the first quartile as the reference. In model 2, we adjusted for age group (35-44, 45-54, 55-64, 65-74, or $\geq 75$ years) and sex variables. In model 3 , we additionally adjusted for body mass index $(<18,18-20.9,21-22.9,23-24.9$, or $\left.\geq 25 \mathrm{~kg} / \mathrm{m}^{2}\right)$, lifestyle factors [including alcohol intake (nondrinker/current), smoking, (yes/no) and exercise (yes/no)], and socioeconomic status [including marital status (single, married, or divorced/separated), educational level ( $<9$ years $/ \geq 9$ years), occupation (no work, manual work, or professional), and family history of CHD (yes/no)]. In model 4, we adjusted for the presence/absence of hypertension and diabetes at baseline along with adjustments for the variables in model 3. In model 5, we included the continuous variables of HDL-C and LDL-C concentrations. In all analyses, we modeled $\mathrm{Lp}(\mathrm{a})$ concentrations as quartiles to avoid the assumption of linearity and to reduce the effects of outliers. Furthermore, we used median Lp(a) concentrations for the categories to test for linear trends across quartiles. We categorized the data ac- 
cording to the 90th, 95th, and 99th percentiles and performed threshold analyses. We also used the test of Hosmer and Lemeshow to evaluate the goodness of fit of the data to the models (20).

All statistical tests were 2-tailed with a type I error of 0.05 , and $P$ values $<0.05$ were considered statistically significant. Analyses were performed with SAS software (version 9.1; SAS Institute) and Stata software (version 9.1; Stata Corporation).

\section{Results}

The participants in the highest $\mathrm{Lp}$ (a) quartile were less likely to drink alcohol and more likely to be in less professional jobs, compared with participants in the lower quartiles (Table 1). Participants had similar distributions across quartiles for female sex, the presence of smoking, regular exercise, marital status, and educational level. In addition, the participants had similar rates across $\operatorname{Lp}(\mathrm{a})$ quartiles for hypertension and diabetes at baseline and for a family history of CHD. A higher $\mathrm{Lp}(\mathrm{a})$ concentration was associated with an older age and higher total cholesterol, LDL-C, and non-HDL cholesterol concentrations but was associated with a lower body mass index and a lower triglyceride concentration. We found no statistically significant differences in mean values for HDL-C, apolipoprotein A-I, or apolipoprotein B across Lp(a) quartiles.

Over a median follow-up of 13.8 years (interquartile range, 13.5-14.6 years) for the 3484 participants, we documented 210 cases of stroke (including 184 nonhemorrhagic and 26 hemorrhagic strokes), 122 cases of CHD, and 781 deaths (including 165 cardiovascular deaths). The incidence rates for each event increased appreciably with $\mathrm{Lp}(\mathrm{a})$ quartile for stroke and all-cause death, and the rates were approximately the same across quartiles for CHD (Table 2). The RRs for individuals in the highest quartile of $\operatorname{Lp}(\mathrm{a})$ concentration compared with those in the lowest quartile were 1.56 [95\% confidence interval (CI), 1.07-2.28; $P$ for trend $=0.003]$ for stroke and 1.26 (95\% CI, 1.031.54 ; $P$ for trend $=0.007)$ for all-cause death. In multivariate analyses adjusted for potential confounding variables, baseline $\mathrm{Lp}(\mathrm{a})$ quartile values were not significantly associated with stroke, all-cause death, or CHD; however, in an evaluation of the risks of $L p(a)$ concentrations greater than or equal to the 90th, 95th, and 99th percentiles (i.e., cutoff concentrations of $0.3443 \mathrm{~g} / \mathrm{L}, 0.4708 \mathrm{~g} / \mathrm{L}$, and $0.6930 \mathrm{~g} / \mathrm{L}$, respectively), the multivariate RR increased with the cutoff value and was statistically significant for stroke at the 90th and 95th percentiles and for all-cause deaths at the 95th and 99th percentiles (Table 3). However, the RRs for CHD showed a statistically nonsignificant increasing trend, with little power.

To address the possibility that the associated risks of $\operatorname{Lp}(\mathrm{a})$ concentration vary by sex and age group, we performed stratified analyses according to participant sex and age and found no modification of the relationship between $\mathrm{Lp}(\mathrm{a})$ concentration and stroke after adjusting for these variables (all interaction $P$ values $>0.1$; data not shown). Among participants older than 65 years, the association between $\mathrm{Lp}$ (a) concentration and stroke remained marginally significant after we adjusted for multivariate risk factors, with the RR increasing from the second through the fourth quartiles (RRs, 1.05, 1.24, and 1.59, respectively; $P$ for trend $=0.055$ ); however, these patterns were not apparent among participants younger than 65 years.

\section{Discussion}

Our data suggest a threshold relationship, with little gradient of risk for stroke and all-cause death across $\mathrm{Lp}$ (a) values among Chinese individuals. We found a marginally significant association between $\mathrm{Lp}$ (a) concentration and stroke only in men 65 years of age and older. Moreover, the strength of the association of $\mathrm{Lp}(\mathrm{a})$ with stroke was attributable to the ischemic subtype of stroke.

Different observational studies have provided conflicting evidence about the role that $\operatorname{Lp}(\mathrm{a})$ concentration plays in stroke. Rigal and colleagues conducted a case-control study of young adults ( $18-55$ years) consisting of 100 cases of ischemic stroke and 100 matched controls and found that the relationship of $\mathrm{Lp}$ (a) concentration with stroke remained significant in men (odds ratio, 3.55; 95\% CI, 1.33-9.48, for the comparison of the highest and lowest tertiles) but not in women (odds ratio, 0.42; 95\% CI, 0.14-1.26) (21). In another case-control study of Japanese individuals, a high $\operatorname{Lp}(\mathrm{a})$ concentration was associated with ischemic stroke (22). The weakness of these studies, however, is that the small sample sizes and the few adjustments for confounding variables may have invalidated the results. Nested case-control studies that retrospectively measured $\mathrm{Lp}(\mathrm{a})$ concentrations in stored samples, which may have been unstable, still did not prove a significant association with further stroke $(8,23)$. Among the 198 incident stroke cases and 198 controls from 7.5 years of follow-up of a cohort of nearly 15000 healthy male physicians, Ridker and colleagues found no association between $\mathrm{Lp}(\mathrm{a})$ concentration and the incidence of stroke (8). 
Table 1. Distribution according to $\mathrm{Lp}(\mathrm{a})$ quartile for various demographic, lifestyle, and socioeconomic factors at baseline in the Chin-Shan Community Cardiovascular Study cohort (1990-1991).

\begin{tabular}{|c|c|c|c|c|c|}
\hline & \multicolumn{4}{|c|}{ Quartile of $L p(a)$ concentration } & \multirow[b]{2}{*}{$P$} \\
\hline & $\begin{array}{c}1 \\
(n=871)\end{array}$ & $\begin{array}{c}2 \\
(n=871)\end{array}$ & $\begin{array}{c}3 \\
(n=871)\end{array}$ & $\begin{array}{c}4 \\
(n=871)\end{array}$ & \\
\hline Sex, \% & & & & & 0.67 \\
\hline Men & 48.1 & 47.1 & 45.8 & 45.5 & \\
\hline Women & 51.9 & 52.9 & 54.2 & 54.5 & \\
\hline Current smoker (yes), \% & 37.8 & 34.2 & 35.9 & 35.9 & 0.49 \\
\hline Alcohol drinking (yes), \% & 34.3 & 28.1 & 27.6 & 29.3 & 0.008 \\
\hline Marital status, $\%$ & & & & & 0.10 \\
\hline Single & 2.8 & 3.6 & 2.4 & 2.4 & \\
\hline Living with spouse & 88.0 & 85.5 & 85.8 & 84.1 & \\
\hline Divorced or separated & 9.2 & 10.9 & 11.8 & 13.5 & \\
\hline Educational level, \% & & & & & 0.14 \\
\hline$<9$ years & 93.3 & 93.2 & 95.2 & 95.1 & \\
\hline$\geq 9$ years & 6.7 & 6.8 & 4.8 & 4.9 & \\
\hline Job status, $\%$ & & & & & $<0.0001$ \\
\hline No job & 46.2 & 49.6 & 51.9 & 53.3 & \\
\hline Manual labor & 33.8 & 33.1 & 34.6 & 34.8 & \\
\hline Professional & 20.1 & 17.3 & 13.6 & 11.9 & \\
\hline Regular exercise (yes), \% & 14.6 & 13.7 & 17.3 & 14.5 & 0.15 \\
\hline Family history of CHD, \% & 11.1 & 9.8 & 8.2 & 9.6 & 0.22 \\
\hline Hypertension, \% & 30.8 & 28.4 & 29.7 & 32.2 & 0.37 \\
\hline Diabetes, \% & 15.1 & 12.0 & 12.3 & 13.9 & 0.19 \\
\hline Age, years ${ }^{a}$ & $53.2(11.5)$ & $54.2(12.5)$ & $55.6(12.2)$ & $56.6(12.8)$ & $<0.0001$ \\
\hline Body mass index, $\mathrm{kg} / \mathrm{m}^{2 a}$ & $24.0(3.6)$ & $23.5(3.4)$ & $23.2(3.3)$ & $23.2(3.3)$ & $<0.0001$ \\
\hline $\mathrm{TC}^{\mathrm{b}}, \mathrm{mmol} / \mathrm{L}^{\mathrm{a}}$ & $4.95(1.11)$ & $5.04(1.16)$ & $5.15(1.18)$ & $5.32(1.21)$ & $<0.0001$ \\
\hline Triglycerides, $\mathrm{mmol} / \mathrm{L}^{\mathrm{a}}$ & $1.65(1.315)$ & $1.46(1.144)$ & $1.32(0.931)$ & $1.28(0.802)$ & $<0.0001$ \\
\hline $\mathrm{HDL}-\mathrm{C}, \mathrm{mmol} / \mathrm{L}^{\mathrm{a}}$ & $1.22(0.36)$ & $1.22(0.32)$ & $1.23(0.31)$ & $1.24(0.31)$ & 0.3 \\
\hline $\mathrm{LDL}-\mathrm{C}, \mathrm{mmol} / \mathrm{L}^{\mathrm{a}}$ & 3.39 (1.09) & $3.49(1.12)$ & $3.61(1.15)$ & $3.76(1.19)$ & $<0.0001$ \\
\hline Non-HDL-C, $\mathrm{mmol} / \mathrm{L}^{\mathrm{a}}$ & $3.72(1.13)$ & $3.82(1.17)$ & $3.92(1.18)$ & $4.07(1.22)$ & $<0.0001$ \\
\hline $\mathrm{TC} / \mathrm{HDL}-\mathrm{C}^{\mathrm{a}}$ & $4.39(1.62)$ & $4.40(1.52)$ & $4.42(1.42)$ & $4.53(1.50)$ & 0.2 \\
\hline Apo A-I, g/L $\mathrm{L}^{\mathrm{a}}$ & $1.360(0.544)$ & $1.323(0.285)$ & $1.338(0.264)$ & $1.327(0.263)$ & 0.1 \\
\hline Apo $B, g / L^{a}$ & $0.953(0.465)$ & $0.941(0.316)$ & $0.978(0.454)$ & $0.969(0.665)$ & 0.4 \\
\hline Apo B/Apo A-1 ${ }^{\mathrm{a}}$ & $0.73(0.40)$ & $0.73(0.25)$ & $0.75(0.34)$ & $0.75(0.52)$ & 0.6 \\
\hline
\end{tabular}

Results based on prospective cohort studies are still inconsistent with respect to the relationship between $\operatorname{Lp}(\mathrm{a})$ concentration and cardiovascular events. Ariyo and colleagues tracked cardiovascular and death events for 3972 older Caucasian adults 65 years and older during 7.4 years of follow-up. These investigators found that $\mathrm{Lp}(\mathrm{a})$ concentration remained a significant predictor of stroke in men but found no relationship with CHD (9). Furthermore, they found no significant association between $\mathrm{Lp}(\mathrm{a})$ concentration and cardiovascular outcomes among older women. In 3.2 years of follow-up of a cohort of 5732 elderly Caucasian men and women who had received statin treatment, Gaw and colleagues found no statistically significant associ- 
Table 2. Incidence cases, person-years, incidence rates, and RRs for stroke, CHD, and all-cause death outcomes during a median follow-up of 13.6 years, according to quartile of $L p(a)$ concentration at baseline $(1990-1991)$ in the Chin-Shan Community Cardiovascular Study. ${ }^{a}$

\begin{tabular}{|c|c|c|c|c|c|}
\hline & \multicolumn{4}{|c|}{ Quartile of $L p(a)$ concentration at baseline } & \multirow[b]{2}{*}{$P$, trend } \\
\hline & 1 & 2 & 3 & 4 & \\
\hline \multicolumn{6}{|l|}{ Stroke } \\
\hline Cases, $\mathrm{n}$ & 47 & 42 & 48 & 68 & \\
\hline Person-years, $n$ & 11044 & 10986 & 10852 & 10578 & \\
\hline Incidence rate & 4.3 & 3.8 & 4.4 & 6.4 & \\
\hline RR, model 1 & 1 & $0.92(0.60-1.40)$ & $1.04(0.69-1.57)$ & $1.56(1.07-2.28)$ & 0.003 \\
\hline RR, model 2 & 1 & $0.85(0.55-1.29)$ & $0.87(0.58-1.31)$ & $1.19(0.81-1.74$ & 0.12 \\
\hline RR, model 3 & 1 & $0.85(0.55-1.30)$ & $0.89(0.58-1.34)$ & $1.23(0.84-1.81)$ & 0.09 \\
\hline RR, model 4 & 1 & $0.88(0.58-1.36)$ & $0.90(0.60-1.37)$ & $1.21(0.83-1.79)$ & 0.13 \\
\hline RR, model 5 & 1 & $0.87(0.56-1.34)$ & $0.90(0.59-1.37)$ & $1.20(0.81-1.78)$ & 0.14 \\
\hline \multicolumn{6}{|l|}{ CHD } \\
\hline Cases, $\mathrm{n}$ & 33 & 25 & 30 & 31 & \\
\hline Person-years, $\mathrm{n}$ & 11086 & 11058 & 10865 & 10693 & \\
\hline Incidence rate & 3 & 2.3 & 2.8 & 2.9 & \\
\hline RR, model 1 & 1 & $0.76(0.45-1.28)$ & $0.93(0.57-1.52)$ & $0.98(0.60-1.60)$ & 0.74 \\
\hline RR, model 2 & 1 & $0.71(0.42-1.20)$ & $0.82(0.50-1.34)$ & $0.81(0.49-1.32)$ & 0.68 \\
\hline RR, model 3 & 1 & $0.76(0.45-1.27)$ & $0.84(0.51-1.40)$ & $0.89(0.54-1.47)$ & 0.95 \\
\hline RR, model 4 & 1 & $0.77(0.46-1.30)$ & $0.86(0.52-1.42)$ & $0.89(0.54-1.47)$ & 0.92 \\
\hline RR, model 5 & 1 & $0.77(0.45-1.30)$ & $0.82(0.49-1.37)$ & $0.81(0.48-1.35)$ & 0.62 \\
\hline \multicolumn{6}{|l|}{ All-cause death } \\
\hline Cases, $\mathrm{n}$ & 175 & 170 & 193 & 211 & \\
\hline Person-years, $\mathrm{n}$ & 11216 & 11151 & 10978 & 10764 & \\
\hline Incidence rate & 15.6 & 15.2 & 17.6 & 19.6 & \\
\hline RR, model 1 & 1 & $0.98(0.79-1.21)$ & $1.13(0.92-1.39)$ & $1.26(1.03-1.54)$ & 0.007 \\
\hline RR, model 2 & 1 & $0.88(0.71-1.09)$ & $0.91(0.74-1.12)$ & $0.93(0.76-1.13)$ & 0.78 \\
\hline RR, model 3 & 1 & $0.88(0.71-1.09)$ & $0.90(0.73-1.11)$ & $0.91(0.74-1.12)$ & 0.68 \\
\hline RR, model 4 & 1 & $0.89(0.72-1.11)$ & $0.91(0.74-1.12)$ & $0.91(0.74-1.12)$ & 0.61 \\
\hline RR, model 5 & 1 & $0.88(0.71-1.09)$ & $0.92(0.74-1.13)$ & $0.91(0.73-1.12)$ & 0.62 \\
\hline \multicolumn{6}{|c|}{$\begin{array}{l}\text { Incidence rates are presented per } 1000 \text { person-years, and RRs are presented as RR }(95 \% \mathrm{Cl}) \text {. Model } 1 \text {, univariate; model 2, adjusted for age group (35-44, } 45-54 \\
55-64,65-74, \geq 75 \text { years) and sex; model 3, model } 2 \text { plus body mass index }\left(<18,18-20.9,21-22.9,23-24.9 \text {, or } \geq 25 \mathrm{~kg} / \mathrm{m}^{2}\right) \text {, smoking (yes/no or abstinence) } \\
\text { current alcohol drinking (regular/no), marital status (single, married and living with spouse, or divorced/separated), educational level }(<9 \text { years } / \geq 9 \text { years) } \\
\text { occupation (no work, manual labor, or official/business), regular exercise (yes/no), and family history of CHD (yes/no); model 4, model } 3 \text { plus hypertension (yes/no } \\
\text { and diabetes mellitus (yes/no); model 5, model } 4 \text { plus HDL-C and LDL-C concentrations. }\end{array}$} \\
\hline
\end{tabular}

ation of log-transformed $\mathrm{Lp}(\mathrm{a})$ concentration with stroke and coronary events in a univariate analysis (10). Among 27791 healthy, mostly Caucasian women in the Women's Health Study who were followed for 10 years, a clear threshold effect was seen for $\operatorname{Lp}(\mathrm{a})$ concentration (7); that is, the association of $\operatorname{Lp}(\mathrm{a})$ with total cardiovascular events remained significant only at extremely high $\mathrm{Lp}$ (a) concentrations. Virtually no risk gradient was seen among these women at the lower $\mathrm{Lp}$ (a) quintiles. Ohira and colleagues examined the as- sociation between $\operatorname{Lp}(\mathrm{a})$ concentration and ischemic stroke in a biracial population of 14221 middle-aged adults followed up for 13.5 years and found an appreciable association in African Americans and Caucasian women, but not in Caucasian men (11). Our data suggest a threshold effect for stroke: the risks of stroke above the 90th and 95th $\mathrm{Lp}(\mathrm{a})$ percentiles were significant, implying that atherosclerotic burdens increased appreciably among individuals with extremely high $\mathrm{Lp}$ (a) concentrations. 


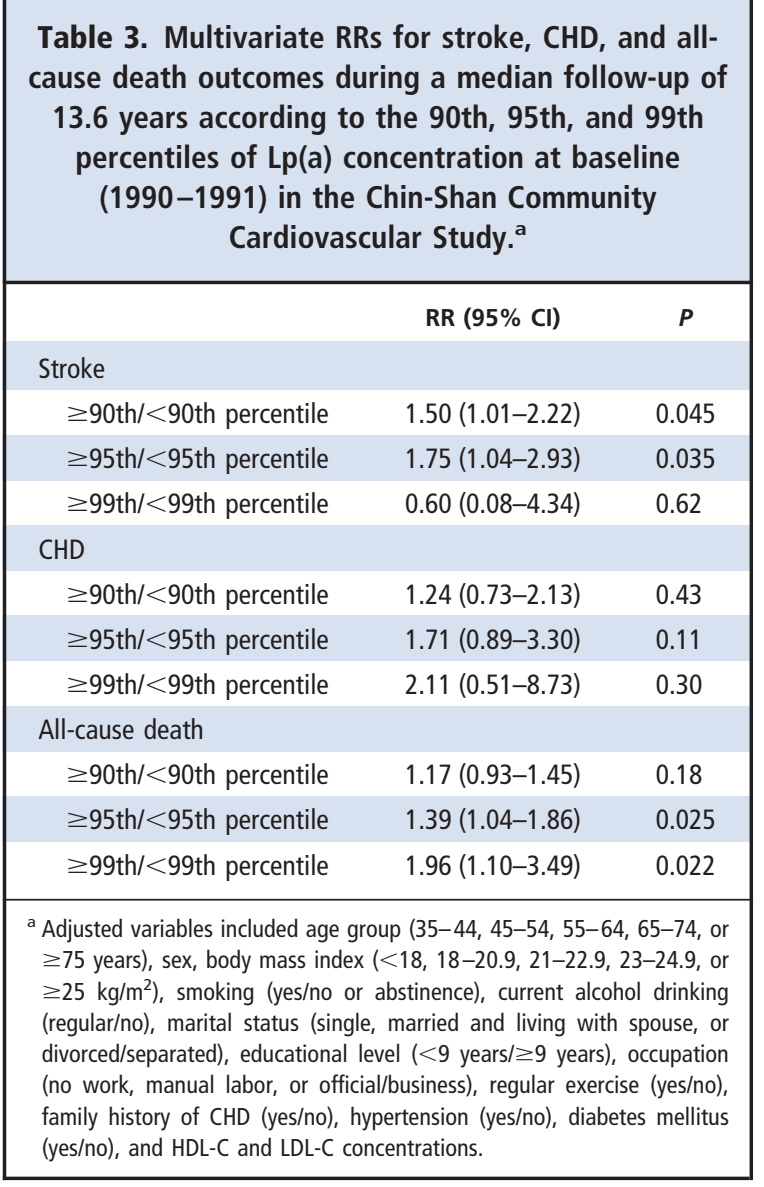

Our negative results with respect to the relationship of $\mathrm{Lp}(\mathrm{a})$ concentration to CHD are comparable with those of previous cohort studies of Caucasian and African American populations $(9,10)$ but are not consistent with the positive association reported in the nested case-control study (24). Rifai and colleagues conducted a nested case-control study and collected $\mathrm{Lp}(\mathrm{a})$ and apolipoprotein(a) data from 195 men who developed severe coronary atherosclerosis during a 5-year follow-up and 195 matched controls in the Physicians' Health Study (24). Although 2 metaanalyses indicated a significant association between $\operatorname{Lp}(\mathrm{a})$ concentration and the risk for CHD, the results may not be valid for different populations because of heterogeneity in participant characteristics and the study $(25,26)$.

The inconsistency of the findings among these different studies is troublesome and begs explanation (27). One proposed explanation has been that Lp(a) interacts with age with respect to further cardiovascular events. Sex, a younger or older age, and the presence of high LDL-C and triglyceride concentra- tions have been reported to modify the association of $\mathrm{Lp}(\mathrm{a})$ concentration with cardiovascular events $(3,7,9,11,21,24)$. Our data suggest a potential relationship among older Chinese men that is compatible with the findings of the Cardiovascular Health Study (9). A specific high-risk population that includes type 2 diabetes and hypercholesterolemia may provide new evidence for the role of $\operatorname{Lp}(\mathrm{a})$ in cardiovascular disease (28).

To our knowledge, this investigation is the first extensive study of $\mathrm{Lp}(\mathrm{a})$ and the risks of stroke, CHD, and all-cause death among ethnic Chinese. Because of the prospective cohort design, the baseline measurements of all cohort members were unlikely to have been affected by storage and laboratory issues that might be raised in some nested case-control studies. The use of a homogeneous community-based population may have reduced the possibility of selection bias. We also included important socioeconomic status and lifestyle factors in the models to control for potential confounding factors. Finally, because few of the participants $(<1 \%)$ reported taking cholesterollowering medications, our results were minimally affected by statins and other cholesterol-lowering drugs.

Our study had several potential limitations. First, the incident cases of stroke and CHD were relatively few, even with a median follow-up of 13.8 years, and this fact would reduce the power to detect subtle differences in effects between $\operatorname{Lp}(\mathrm{a})$ concentrations and make RR estimation unstable. Second, because Lp(a) concentrations were measured only once, our results might be attenuated by intraindividual variations.

In conclusion, our data do not support the hypothesis that an increase in $\mathrm{Lp}(\mathrm{a})$ concentration, over most of its range, is significantly associated with stroke, CHD, or all-cause death among ethnic Chinese adults. Only a small proportion of people with extremely high $\mathrm{Lp}(\mathrm{a})$ concentrations were at excess risk. These findings limit the use of $\operatorname{Lp}(\mathrm{a})$ as a biomarker for the comprehensive evaluation of risk for cardiovascular disease in Chinese populations; however, a single measure of $\operatorname{Lp}(\mathrm{a})$ concentration to identify the small subgroup with extreme values may have some utility.

Grant/funding Support: This study was supported by a grant from the National Science Council in Taiwan (NSC 96-2314-B-002-155).

Financial Disclosures: None declared.

Acknowledgments: We thank the participants in the Chin-Shan community and the cardiologists at $\mathrm{Na}$ tional Taiwan University Hospital for their assistance in this study. 


\section{References}

1. Loscalzo J. Lipoprotein(a). A unique risk factor for atherothrombotic disease. Arteriosclerosis 1990; 10:672-9.

2. Gaubatz JW, Heideman C, Gotto AM Jr, Morrisett JD, Dahlen GH. Human plasma lipoprotein [a]. Structural properties. J Biol Chem 1983;258: 4582-9.

3. Frohlich J, Dobiásová $M$, Adler L, Francis $M$. Gender differences in plasma levels of lipoprotein (a) in patients with angiographically proven coronary artery disease. Physiol Res 2004;53:481-6.

4. Jovicic A, Ivanisevic V, Ivanovic I. Lipoprotein(a) in patients with carotid atherosclerosis and ischemic cerebrovascular disorders. Atherosclerosis 1993;98:59-65.

5. Pantoni L, Sarti C, Pracucci G, Di CA, Vanni $P$, Inzitari D. Lipoprotein(a) serum levels and vascular diseases in an older Caucasian population cohort. Italian Longitudinal Study on Aging (ILSA). J Am Geriatr Soc 2001;49:117-25.

6. Jones GT, van Rij AM, Cole J, Williams MJ, Bateman EH, Marcovina SM, et al. Plasma lipoprotein(a) indicates risk for 4 distinct forms of vascular disease. Clin Chem 2007;53:679-85.

7. Suk Danik J, Rifai N, Buring JE, Ridker PM. Lipoprotein(a), measured with an assay independent of apolipoprotein(a) isoform size, and risk of future cardiovascular events among initially healthy women. JAMA 2006;296:1363-70.

8. Ridker PM, Stampfer MJ, Hennekens CH. Plasma concentration of lipoprotein(a) and the risk of future stroke. JAMA 1995;273:1269-73.

9. Ariyo $A A$, Thach $C$, Tracy $R$, for the Cardiovascular Health Study investigators. Lp(a) lipoprotein, vascular disease, and mortality in the elderly. N Engl J Med 2003;349:2108-15.

10. Gaw A, Murray HM, Brown EA, the PROSPER study group. Plasma lipoprotein(a) [Lp(a)] concentrations and cardiovascular events in the elderly: evidence from the Prospective Study of Pravastatin in the Elderly at Risk (PROSPER). Atherosclerosis 2005;180:381-8.
11. Ohira T, Schreiner PJ, Morrisett JD, Chambless LE, Rosamond WD, Folsom AR. Lipoprotein(a) and incident ischemic stroke: the Atherosclerosis Risk in Communities (ARIC) study. Stroke 2006;37: 1407-12.

12. Lee $Y T$, Lin RS, Sung FC, Yang $C Y$, Chien $K L$, Chen WJ, et al. Chin-Shan Community Cardiovascular Cohort in Taiwan: baseline data and five-year follow-up morbidity and mortality. J Clin Epidemiol 2000;53:836-46.

13. Chien KL, Lee YT, Sung FC, Su TC, Hsu HC, Lin RS. Lipoprotein (a) level in the population in Taiwan: relationship to sociodemographic and atherosclerotic risk factors. Atherosclerosis 1999;143:26773.

14. Chien $\mathrm{KL}$, Hsu $H C$, Sung $F C$, Su TC, Chen MF, Lee YT. Metabolic syndrome as a risk factor for coronary heart disease and stroke: an 11-year prospective cohort in Taiwan community. Atherosclerosis 2007;194:214-21.

15. Chien KL, Sung FC, Hsu HC, Su TC, Chang WD, Lee YT. Relative importance of atherosclerotic risk factors for coronary heart disease in Taiwan. Eur J Cardiovasc Prev Rehabil 2005;12: 95-101.

16. Chien KL, Sung FC, Hsu HC, Su TC, Lin RS, Lee YT. Apolipoprotein A-I and B and stroke events in a community-based cohort in Taiwan: report of Chin-Shan Community Cardiovascular Study. Stroke 2002;33:39-44.

17. Chien KL, Lee YT, Sung FC, Hsu HC, Su TC, Lin RS. Hyperinsulinemia and related atherosclerotic risk factors in the population at cardiovascular risk: a community-based study. Clin Chem 1999;45: 838-46.

18. Wieland $H$, Seidel D. A simple specific method for precipitation of low density lipoproteins. J Lipid Res 1983:24:904-9.

19. Siedel J, Schiefer $S$, Rosseneu M, Bergeaud R, De Keersgieter W, Pautz B, et al. Immunoturbidimetric method for routine determinations of apolipoproteins A-I, A-II, and B in normo- and hyper- lipemic sera compared with immunonephelometry. Clin Chem 1988;34:1821-5.

20. Hosmer DW Jr, Lemeshow S. Applied logistic regression. New York: John Wiley \& Sons, 1989: 25-37.

21. Rigal $M$, Ruidavets JB, Viguier $A$, Petit $R$, Perret $B$, Ferrieres J, Larrue V. Lipoprotein (a) and risk of ischemic stroke in young adults. J Neurol Sci 2007;252:39-44.

22. Nagayama $M$, Shinohara $Y$, Nagayama T. Lipoprotein (a) and ischemic cerebrovascular disease in young adults. Stroke 1994;25:74-8.

23. Glader CA, Stegmayr B, Boman J, Stenlund $H$, Weinehall L, Hallmans G, Dahlen GH. Chlamydia pneumoniae antibodies and high lipoprotein(a) levels do not predict ischemic cerebral infarctions. Results from a nested case-control study in Northern Sweden. Stroke 1999;30:2013-8.

24. Rifai N, Ma J, Sacks FM, Ridker PM, Hernandez WJ, Stampfer MJ, Marcovina SM. Apolipoprotein(a) size and lipoprotein(a) concentration and future risk of angina pectoris with evidence of severe coronary atherosclerosis in men: the Physicians' Health Study. Clin Chem 2004;50:136471.

25. Craig WY, Neveux LM, Palomaki GE, Cleveland MM, Haddow JE. Lipoprotein(a) as a risk factor for ischemic heart disease: metaanalysis of prospective studies. Clin Chem 1998;44:2301-6.

26. Danesh J, Collins R, Peto R. Lipoprotein(a) and coronary heart disease. Meta-analysis of prospective studies. Circulation 2000;102:1082-5.

27. Berglund L, Ramakrishnan R. Lipoprotein(a): an elusive cardiovascular risk factor. Arterioscler Thromb Vasc Biol 2004;24:2219-26.

28. Shai I, Schulze MB, Manson JE, Stampfer MJ, Rifai $\mathrm{N}$, Hu FB. A prospective study of lipoprotein(a) and risk of coronary heart disease among women with type 2 diabetes. Diabetologia 2005;48: 1469-76. 